\title{
PEMANFAATAN GLISEROL DARI PRODUK SAMPING BIODIESEL UNTUK SINTESIS SENYAWA 2,3-DIBROMO PROPANOL
}

\author{
Dewi Sinta Megawati ${ }^{1}$, Jumina, Harno Dwi Pranowo \\ 1Jurusan Farmasi, Fakultas Sains dan Teknologi, Universitas Islam Negeri Maulana \\ Malik Ibrahim Malang, Malang Indonesia \\ 2Jurusan Kimia Fakultas Matematika dan Ilmu Pengetahuan Alam \\ Universitas Gadjah Mada, Yogyakarta
}

\begin{abstract}
ABSTRAK
Telah dilakukan sintesis senyawa 2,3-dibromo propanol menggunakan bahan awal gliserol hasil isolasi produk samping pembuatan biodiesel. Peningkatan yang cepat dalam produksi biodiesel diperkirakan akan mengakibatkan surplus gliserol. Penggunaan gliserol sebagai bahan awal bertujuan meningkatkan nilai ekonomis dari gliserol itu sendiri. Gliserol dengan rendemen $88,7 \%$ telah diisolasi dari produk samping pembuatan biodiesel melalui reaksi transesterifikasi trigliserida dalam minyak sawit menggunakan katalis basa $\mathrm{KOH}$. Selanjutnya, gliserol didehidrasi dengan asam format untuk mendapatkan senyawa alil alkohol melalui metode destilasi pada 195-260 ${ }^{0} \mathrm{C}$. Sintesis senyawa 2,3-dibromo propanol dicapai melalui brominasi alil alkohol pada -2-0 ${ }^{0} \mathrm{C}$ menggunakan pelarut khloroform. Karakterisasi struktur dilakukan menggunakan spektrometer IR, ${ }^{1} \mathrm{H}-\mathrm{NMR}$, dan GC-MS. Pada penelitian ini, alil alkohol yang diperoleh melalui metode destilasi memiliki rendemen sebesar $44,78 \%$ dan reaksi brominai alil alkohol menghasilkan senyawa 2,3-dibromo propanol dengan rendemen $80,3 \%$ yield.
\end{abstract}

Keywords : senyawa 2,3-dibromo propanol, gliserol, biodiesel

\section{PENDAHULUAN}

Gliserol (atau biasa disebut gliserin) merupakan senyawa alifatik dengan tiga atom karbon yang masing-masing mengikat gugus hidroksil $(-\mathrm{OH})$. Senyawa ini dapat dihasilkan dari reaksi transesterifikasi, saponifikasi, hidrolisis dan aminolisis trigliserida (triasilgliserol). Biodiesel merupakan bahan bakar yang terbuat dari minyak nabati, minyak hewani, atau minyak goreng bekas/daur ulang (bahan alam terbarukan) juga diproses melalui reaksi transesterifikasi antara trigliserida dengan basa menghasilkan gliserol sebagai produk samping.

Krisis bahan bakar minyak menyebabkan kenaikan harga minyak mentah dunia, sehingga saat ini biodiesel dijadikan sebagai sumber energi atau bahan bakar alternatif untuk komponen pencampur dalam minyak diesel ataupun sebagai bahan bakar pengganti minyak diesel. Selain karena alasan tersebut, produksi biodiesel sedang marak dilakukan oleh banyak negara, termasuk Indonesia karena biodiesel bersifat non-toksik dan biodegradable [1]. Oleh karena itu, dapat diperkirakan bahwa jika produksi biodiesel semakin meningkat, maka gliserol yang dihasilkan juga akan semakin banyak. Setiap ton biodiesel yang dihasilkan, akan diperoleh $100 \mathrm{Kg}$ gliserol [6] atau akan diperoleh perbandingan berat gliserol/biodiesel 1:10 [2]. Secara global, produksi gliserol akan menjadi 4,5 juta ton dalam tahun 2010 [6].

Pemanfaatan gliserol dari produk samping biodiesel belum banyak dilakukan. Cardona dkk, (2007) telah memanfaatkan gliserol hasil produk samping biodiesel menjadi produk 
bernilai tambah, yaitu sintesis senyawa 1,3-propana-diol. Oleh karena itu, pada penelitian ini dilakukan sintesis senyawa 2,3-dibromo propanol menggunakan bahan awal gliserol hasil isolasi produk samping biodiesel untuk meningkatkan nilai ekonomis dari gliserol tersebut. Senyawa 2,3-dibromo propanol merupakan senyawa yang dapat digunakan dalam sintesis senyawa antidotum dimerkaprol (British anti-Lewisite/BAL; 2,3 dimerkapto propanol) [7] yang dikenal sebagai senyawa antidotum sejak perang dunia II dan digunakan secara klinis dalam pengobatan keracunan arsen (As) sejak tahun 1949 [3].

\section{METODE PENELITIAN Bahan}

Bahan utama yang digunakan pada penelitian ini adalah minyak sawit (merk Tropical), kalium hidroksida $(\mathrm{KOH})$, metanol, asam format, natrium hidroksida $(\mathrm{NaOH})$, bromin $\left(\mathrm{Br}_{2}\right)$, kloroform $\left(\mathrm{CHCl}_{3}\right)$, natrium sulfat $\left(\mathrm{Na}_{2} \mathrm{SO}_{4}\right)$ anhidrat. Selain minyak sawit, semua bahan tersebut berasal dari Merck dengan kualitas pro analitik (p.a).

\section{Alat}

Alat-alat yang digunakan dalam penelitian ini adalah satu set alat refluks, satu set alat destilasi fraksinasi pengurangan tekanan, alat-alat gelas laboratorium, termometer, alat timbang elektrik (Libror EB-330 Shimadzu), satu set alat evaporator Büchii tipe R-124, pemanas stirer (hot plate), magnet stirer, Spektrometer Inframerah (IR, Shimadzu 8201-PC), Kromatografi Gas-Spektrometer Massa (GC-MS, Shimadzu QP-2010S), dan Spektrometer Resonansi Magnetik Inti Proton ( ${ }^{1} \mathrm{H}-\mathrm{NMR}$, JNM-MY, $\left.60 \mathrm{MHz}\right)$.

\section{Prosedur Isolasi gliserol}

Sejumlah minyak sawit $(B M=$ 847,28 g.mol ${ }^{-1}$ [4]) dipanaskan pada temperatur $110^{\circ} \mathrm{C}$ selama 30 menit dengan tujuan untuk menghilangkan air yang mungkin terkandung di dalamnya.

Transesterifikasi minyak sawit dilakukan dengan menimbang $100 \mathrm{~g}$ minyak sawit bebas air dalam labu leher tiga $250 \mathrm{~mL}$. Dibuat larutan kalium metoksida dengan cara menimbang $1 \mathrm{~g}$ $\mathrm{KOH}(1 \%$ b/b KOH terhadap berat minyak) dan dilarutkan dalam 29,20 mL metanol untuk memperoleh rasio molar metanol $/$ minyak = 9:1. Selanjutnya larutan kalium metoksida dimasukkan ke dalam minyak sawit yang telah dipanaskan. Campuran diaduk dan direfluks selama 2 jam pada temperatur $70^{\circ} \mathrm{C}$. Setelah reaksi transesterifikasi selesai, produk didiamkan sekitar 15 menit sehingga diperoleh 2 lapisan. Lapisan bawah yang merupakan lapisan gliserol diambil menggunakan corong pisah dan kemudian dievaporasi. Selanjutnya didestilasi pengurangan tekanan. Hasil dianalisis dengan Spekterometer IR, ${ }^{1} \mathrm{H}-\mathrm{NMR}$ dan GC-MS.

\section{Sintesis alil alkohol}

Gliserol sebanyak $21,90 \mathrm{~mL} \quad(0,3$ $\mathrm{mol}$ ) dan asam format sebanyak 7,54 $\mathrm{mL}(0,2 \mathrm{~mol})$ dimasukkan ke dalam labu leher tiga $250 \mathrm{~mL}$ yang telah dilengkapi dengan set kondensor destilasi. Campuran didestilasi sampai temperatur mencapai $260^{\circ} \mathrm{C}$. Pada temperatur $195^{\circ} \mathrm{C}$ ( sekitar 20-30 menit) destilat diambil dan dikumpulkan secara terpisah. Pemanasan dilanjutkan sampai temperatur mencapai $260^{\circ} \mathrm{C}$, destilat ditampung lagi (destilat $260^{\circ} \mathrm{C}$ I). Setelah destilat dikumpulkan, labu didinginkan sampai temperatur mencapai $100^{\circ} \mathrm{C}$, kemudian ditambahkan dengan 5,3 $\mathrm{mL}(0,14 \mathrm{~mol})$ asam format. Selanjutnya didestilasi lagi seperti prosedur sebelumnya dan destilat ditampung pada temperatur $195-260^{\circ} \mathrm{C}$ (destilat $260^{\circ} \mathrm{C}$ II). Labu didinginkan lagi sampai mencapai temperatur $100^{\circ} \mathrm{C}$ dan ditambahkan asam format sebanyak $5,3 \mathrm{~mL}(0,14$ mol) dan didestilasi seperti prosedur sebelumnya (destilat $260^{\circ} \mathrm{C}$ III). Semua destilat (destilat I, II, III) yang 
ditampung pada temperatur antara 195$260^{\circ} \mathrm{C}$ dikumpulkan dan ditambah dengan $\mathrm{NaOH}$ pellet secukupnya (untuk menetralkan adanya sedikit asam format). Selanjutnya dikeringkan dengan $\mathrm{Na}_{2} \mathrm{SO}_{4}$ anhidrat kemudian didestilasi dan destilat pada temperatur sekitar $97^{\circ} \mathrm{C}$ diambil. Hasilnya dianalisis dengan spektrometer IR, ${ }^{1} \mathrm{H}-\mathrm{NMR}$ dan GC-MS.

\section{Brominasi alil alkohol}

Alil alkohol sebanyak $5,5 \mathrm{~mL}(0,08$ mol; 4,65 g) dilarutkan dengan $25 \mathrm{~mL}$ $\mathrm{CHCL}_{3}$ dalam labu leher tiga kapasitas $100 \mathrm{~mL}$ yang telah dilengkapi dengan pengaduk magnet, corong penetes dan pendingin balik.

Dibuat larutan 4,1 mL Br 2 (0,08 mol; $12,78 \mathrm{~g})$ dalam $25 \mathrm{~mL} \quad \mathrm{CHCL}_{3}$ kemudian ditambahkan ke dalam labu secara bertetes-tetes. Suhu dijaga agar tetap pada $-2-0^{\circ} \mathrm{C}$ dengan menggunakan pendingin campuran serbuk es dan garam dapur. Setelah semua larutan $\mathrm{Br}_{2}$ telah habis, pengadukan diteruskan sampai 1 jam. Selanjutnya hasil reaksi dievaporasi dan residu

\section{HASIL DAN PEMBAHASAN}

Gliserol dalam penelitian ini dihasilkan melalui reaksi transesterifikasi minyak sawit, dimana metode tersebut juga merupakan metode yang biasa digunakan dalam pembuatan biodiesel (metil ester). Reaksi transesterifikasi merupakan reaksi kesetimbangan (reaksi reversibel), sehingga digunakan katalis basa kalium hidroksida $(\mathrm{KOH})$ untuk mempercepat tercapainya kesetimbangan. Sedangkan alkohol dibuat berlebih untuk menghasilkan produk ester yang banyak. Dengan semakin meningkatnya konsentrasi alkil ester, maka akan diikuti dengan meningkatnya konsentrasi gliserol yang dibebaskan molekul trigliserida. Namun demikian, proporsi pembentukan gliserol tidak selalu sama dengan pembentukan ester. Hal ini dipengaruhi oleh produk antara yang terbentuk seperti digliserida dan monogliserida [8]. Hasil akhir dari reaksi transesterifikasi adalah terbentuknya campuran yang terdiri dari 2 fasa, dimana fasa atas merupakan metil ester dan fasa bawah adalah gliserol. Fasa metil ester berwarna kekuningan sedangkan fasa gliserol berwarna lebih gelap.

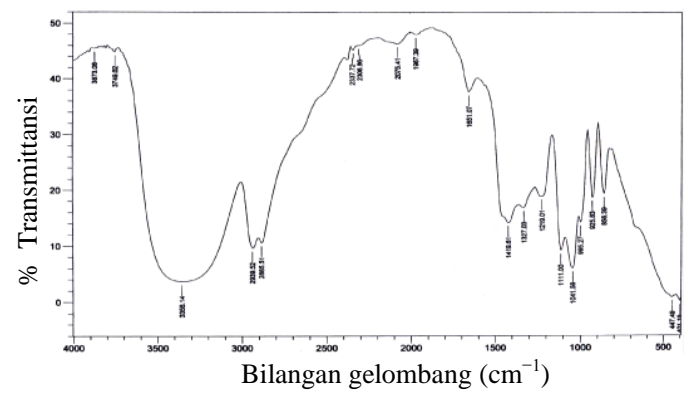

Gambar 1. Spektra IR gliserol

Analisis struktur menggunakan spektrometer IR (Gambar 1) menunjukkan bahwa serapan melebar dengan intensitas sedang pada daerah 3356,14 $\mathrm{cm}^{-1}$ menunjukkan adanya vibrasi rentangan gugus hidroksi $(-\mathrm{OH})$ alkohol dan serapan tajam pada bilangan gelombang 2939,52 dan $2885,51 \mathrm{~cm}^{-1}$ merupakan karakteristik serapan gugus alkil oleh vibrasi rentangan $\mathrm{C}_{\mathrm{sp}}{ }^{3}-\mathrm{H}$, diperkuat oleh serapan pada daerah 1419,61 $\mathrm{cm}^{-1}$ yang menunjukkan vibrasi bengkokan $\mathrm{C}-\mathrm{H}$ gugus metilen $\left(-\mathrm{CH}_{2}-\right)$.

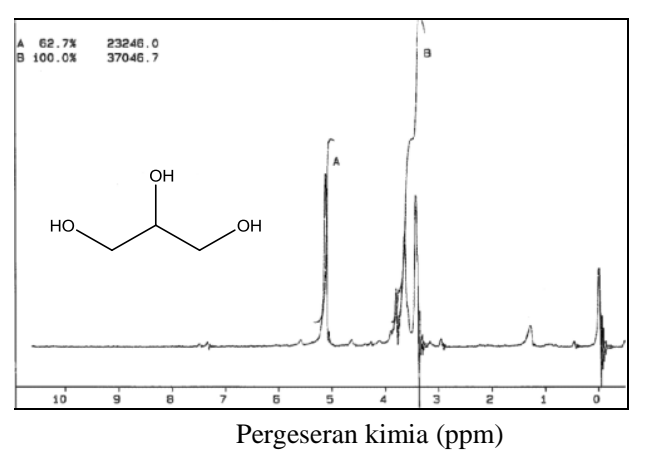

Gambar 2. Spektra ${ }^{1} \mathrm{H}-\mathrm{NMR}$ gliserol

Spektra ${ }^{1} \mathrm{H}$-NMR (Gambar 2) terhadap produk yang disintesis menunjukkan adanya 2 daerah pergeseran kimia. Sinyal $A$ pada $\delta=$ 
5,20-5,10 ppm dengan kenampakan singlet diperkirakan berasal dari gugus hidroksil $(-\mathrm{OH})$ dan sinyal B $(\delta 3,80-$ $3,40 \mathrm{ppm}$, multiplet, $5 \mathrm{H}$ ) berasal dari proton-proton $\mathrm{C}-1, \mathrm{C}-2$ dan C-3.

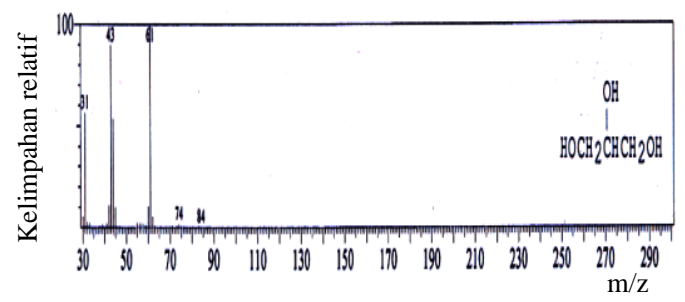

Gambar 3. Spektra massa gliserol

Untuk membuktikan bahwa produk yang disintesis adalah gliserol, senyawa yang dihasilkan kemudian dianalisis menggunakan spektrometer GC-MS. Spektra GC-MS ditunjukkan pada Gambar 3. Meskipun tidak terlihat puncak ion molekuler $\left(\mathrm{M}^{+}\right)$pada $\mathrm{m} / \mathrm{z} 92$ yang merupakan berat molekul senyawa gliserol, ini mengindikasikan bahwa senyawa tersebut tidak stabil sehingga langsung mengalami fragmentasi $\mathrm{m} / \mathrm{z} 84$. Puncak pada $\mathrm{m} / \mathrm{z}$ 61 merupakan puncak dasar (base peak) yang berasal dari pelepasan radikal $\mathrm{CH}_{2} \mathrm{OH}$. Dapat disimpulkan bahwa produk hasil isolasi produk samping biodiesel merupakan gliserol dengan rendemen $88,7 \%$.

\section{Sintesis alil alkohol}

Sintesis alil alkohol dilakukan dengan mereaksikan gliserol dengan asam format dengan metode destilasi. Destilasi dilakukan dengan 3 tahapan penambahan asam format sebab diperkirakan masih terdapat gliserol yang belum bereaksi. Semua destilat yang terkumpul pada temperatur 196$260{ }^{\circ} \mathrm{C}$ diambil dan ditambahkan dengan $\mathrm{NaOH}$ untuk menetralkan adanya sedikit asam format. Akan tetapi, penambahan $\mathrm{NaOH}$ berlebih menyebabkan terbentuknya 2 lapisan/fase. Penambahan $\mathrm{NaOH}$ juga berfungsi untuk mengisolasi alil alkohol. Alil alkohol dapat larut dalam air, namun dengan adanya $\mathrm{NaOH}$ menyebabkan air bertambah kepolarannya sedangkan alil alkohol tetap. Oleh karena itu, terbentuk 2 lapisan, dimana air berada dilapisan bawah dan alil alkohol berada dilapisan atas. Alil alkohol memiliki rendemen $44,78 \%$. Reaksi yang terjadi antara gliserol dengan asam format merupakan reaksi dehidrasi alkohol.

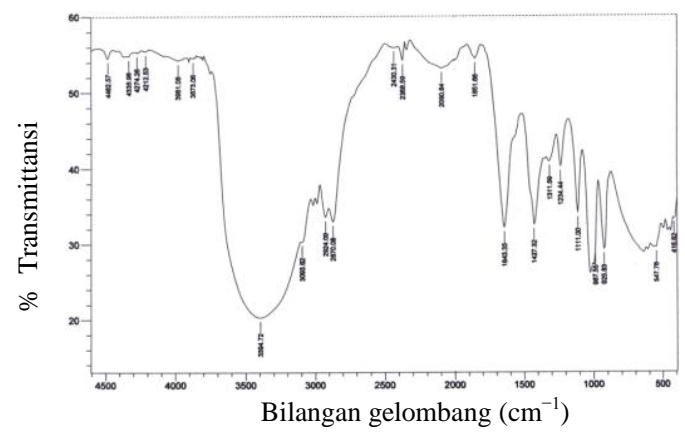

Gambar 4. Spektra FT-IR alil alkohol

Adanya vibrasi gugus hidroksil (-OH) sebagai substituen dibuktikan oleh serapan tajam dan lebar pada daerah $3417,86 \mathrm{~cm}^{-1}$. Serapan yang sangat lemah pada daerah 3093,82 $\mathrm{cm}^{-1}$ merupakan serapan akibat vibrasi rentangan $=\mathrm{C}-\mathrm{H}\left(\mathrm{C}_{\mathrm{sp}}{ }^{2}-\mathrm{H}\right)$. Serapan yang tajam dengan intensitas kuat pada daerah 1643,35 $\mathrm{cm}^{-1}$ menunjukkan adanya ikatan rangkap karbon-karbon (-C=C- alkena).

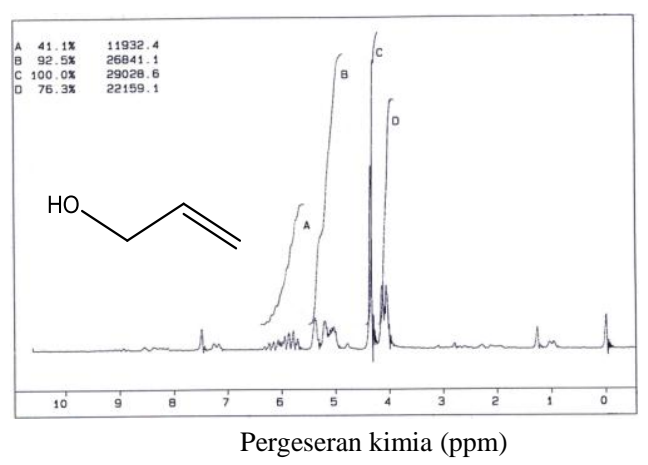

Gambar 5. Spektra ${ }^{1} \mathrm{H}-\mathrm{NMR}$ alil alkohol

Serapan kecil dengan intensitas lemah pada daerah 3000-2950 $\mathrm{cm}^{-1}$ merupakan karakteristik serapan gugus -C-H vinil yang menunjukkan bahwa posisi gugus alkena berada di terminal. Hal ini diperkuat oleh adanya serapan 
tajam dengan intensitas sedang akibat vibrasi bengkok keluar bidang pada daerah 925,83 $\mathrm{cm}^{-1}$.

Spektra ${ }^{1} \mathrm{H}-\mathrm{NMR}$ (Gambar 5) terhadap produk hasil sintesis menunjukkan adanya 4 daerah pergeseran kimia. Pergeseran kimia pada $\delta=6,4-5,6 \mathrm{ppm}$ dengan kenampakan multiplet $(1 \mathrm{H})$ diprediksi berasal dari proton pada atom $\mathrm{C}-2$ yang berikatan rangkap dua. Sinyal B $(\delta 5,4-$ 4,9 ppm, doublet-doublet, 2H) merupakan puncak akibat resonansi proton-proton gugus metilen (cis dan trans) dari atom C-3. Sinyal C ( $\delta 4,8$ ppm, doublet, $2 \mathrm{H}$ ) adalah puncak dari atom C-1 dan sinyal D ( $\delta$ 4,2 ppm, singlet, $1 \mathrm{H}$ ) berasal dari proton hidroksil $(-\mathrm{OH})$.

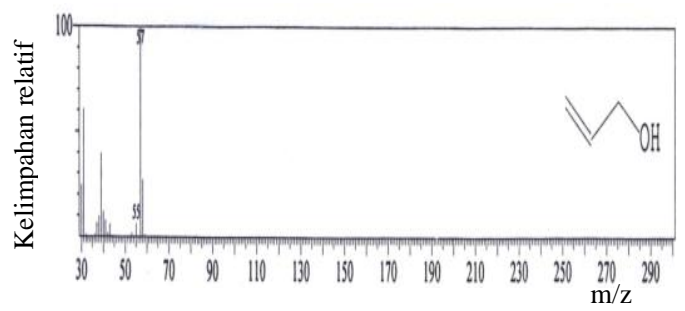

Gambar 6. Spektra massa alil alkohol

Spektra GC-MS alil alkohol ditunjukkan pada Gambar 6. Puncak ion molekuler pada $\mathrm{m} / \mathrm{z}=58$ sesuai dengan berat molekul alil alkohol.

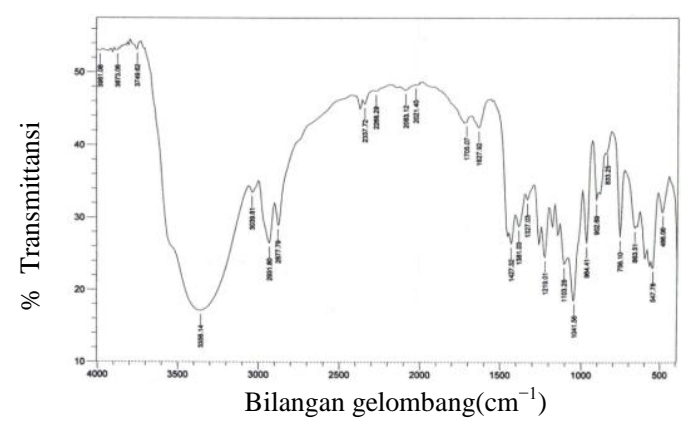

Gambar 7. Spektra IR 2,3-dibromo propanol

\section{Brominasi alil alkohol}

Brominasi alil alkohol dilakukan pada temperatur dibawah $-5{ }^{\circ} \mathrm{C}$ sebab reaksi yang terjadi antara alil alkohol dan bromin $\left(\mathrm{Br}_{2}\right)$ merupakan reaksi eksoterm (pelepasan panas). Hasil brominasi menghasilkan larutan sedikit kental berwarna jingga (kuning kecoklatan) dengan rendemen $86 \%$.

Berdasarkan spektra IR produk yang dihasilkan (Gambar 7) menunjukkan bahwa serapan ikatan rangkap karbon-karbon $(-\mathrm{C}=\mathrm{C}$ - alkena) pada $1643,35 \mathrm{~cm}^{-1}$ tidak terlihat. Hal ini mengindikasikan bahwa reaksi brominasi telah terjadi. Bukti kuat lain bahwa reaksi telah berhasil dilakukan adalah munculnya pita serapan pada $690-515 \mathrm{~cm}^{-1}$ yang karakteristik untuk ikatan $\mathrm{C}-\mathrm{Br}$ [5] dan pita serapan pada 1250-1150 $\mathrm{cm}^{-1}$ untuk vibrasi bengkokan untuk $\mathrm{CH}_{2}-\mathrm{Br}$.

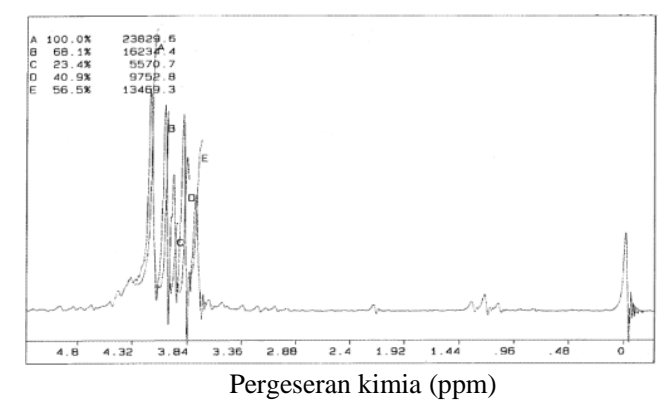

Gambar 8. Spektra ${ }^{1} \mathrm{H}-\mathrm{NMR} 2,3-$ dibromo propanol (0-5 ppm)

Berdasarkan analisis spektra ${ }^{1} \mathrm{H}$ NMR (Gambar 8), juga dapat disimpulkan bahwa brominasi alil alkohol menggunakan $\mathrm{Br}_{2}$ telah berhasil dilakukan. Hal ini ditunjukkan oleh hilangnya proton-proton alkena pada $\delta$ 6,4-4,9 ppm dari alil alkohol. Ini mengindikasikan bahwa produk tidak lagi mengandung ikatan rangkap karbon-karbon, tetapi telah tersubstitusi oleh $\mathrm{Br}$.

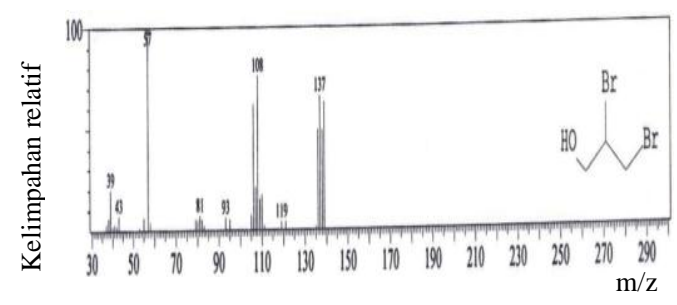

Gambar 9. Sp[ektra massa 2,3dibromo propanol 
Spektra GC-MS 2,3-dibromo propanol ditunjukkan pada Gambar 9. Puncak pada $\mathrm{m} / \mathrm{z} 137\left(\mathrm{M}-{ }^{79} \mathrm{Br}\right)$ dan $\mathrm{m} / \mathrm{z}$ $139\left(\mathrm{M}-{ }^{81} \mathrm{Br}\right)$ terlihat merupakan puncak kembar yang berjarak 2 sma (was showed as a twin peaks which had the distance of 2 sma (Puncak yang memiliki intensitas hampir sama), begitupun dengan puncak pada $\mathrm{m} / \mathrm{z}$ 136 and $\mathrm{m} / \mathrm{z}$ 138. Adanya 2 puncak tersebut disebabkan karena atom $\mathrm{Br}$ mempunyai 2 isotop di alam $\left({ }^{79} \mathrm{Br}\right.$ and ${ }^{81} \mathrm{Br}$ ) [5]. Puncak dengan $\mathrm{m} / \mathrm{z} \quad 57$ merupakan puncak dasar dari spektra tersebut.

\section{KESIMPULAN}

Gliserol yang dihasilkan melalui reaksi transesterifikasi minyak sawit, yang juga merupakan metode dalam pembuatan biodiesel memiliki rendemen 88,7 \%. Hasil reaksi dehidrasi gliserol dengan asam format menghasilkan alil alkohol dengan rendemen 44,78 \% dan reaksi bromonasi alil alkohol menghasilkan senyawa 2,3-dibromo propanol dengan rendemen $86 \%$.

\section{DAFTAR PUSTAKA}

1. Bajpai, D., Tyagi, V.K., 2006, Review; Biodiesel: Source, Production, Composition, Properties and its benefits, J. of Oleo Science, 55(10):487-502.

2. Cardona, C., Posada, J., dan Montoya, M., 2007, Use of Glycerol from Biodiesel Production: Conversion to Added Value Products, Proceedings of European Congress of Chemical Engineering (ECCE-6), 16-20 September, Copenhagen.

3. Flora, S.J.S., Mittal, M., dan Mehta, A., 2008, Heavy Metal Induced Oxidative Stress \& Its Possible Reversal by Chelation Therapy, Indian J.Med Res, 501-523.

4. Lele, S, 2005, Oil Yields and Characteristics, http://www.svlele.com, 21 February 2005.

5. Silverstein, R.M., Bassler, G.C., dan Morrill, T.C., 1991, Spectrometric Identification of Organic Compounds, Edisi 5, John Wiley and Sons, Inc., New York.

6. Siqueira, B.G., Junior, M.G., Menezes, R.B., dan Rabello, C.R.K., 2008, Renewable Cetane Improver from Glycerin of Biodiesel, $2^{\text {nd }}$ International IUPAC Conference on Green Chemistry, Russia, 14-19 September, PETROBRAS, crkr@petrobras.com.br.

7. Windholz, M., 1983, The Merck Index, Edisi Kesepuluh, Merck \& Co., Inc., New York, 3198.

8. Yoeswono, 2007, Kinetika Transesterifikasi Minyak Sawit dalam Metanol dengan Katalis Kalium Hidroksida dalam Sintesis Biodiesel, Tesis, FMIPA Universitas GadjahMada, Yogyakarta. 